БОЛЬШАКОВА Юлия Михайловна - кандидат политических наук, старший научный сотрудник Института политической психологии и прикладных политических исследований Ленинградского государственного университета им. А.С. Пушкина (196605, Россия, г. Санкт-Петербург, Пушкин, Петербургское ш., 10; academy.prof.com@gmail.com)

\title{
В ПОИСКАХ ПАРАДИГМЫ ПУБЛИЧНОГО УПРАВЛЕНИЯ: КОНСЦЕНТИАНЕТИКА - СОЗНАТЕЛЬНОЕ УПРАВЛЕНИЕ
}

Аннотация. В работе предложена концепция сознательного управления, претендующая на роль парадигмы современного публичного управления. Автор показывает, что объективной причиной кризиса современного публичного управления является возросшая динамика человекоразмерных изменений социально-политической жизни современных обществ. В качестве субъективных причин установлено использование теорий, исходящих из формальной логики и блокирующих творческий потенциал субъекта управления. Автор предлагает новый методологический подход, в основе которого лежит гипотеза о существовании единых механизма, закономерностей и условий формирования обыденного и любого деятельностно ориентированного (в частности, управленческого) сознания. Этот сознаниецентрический подход назван автором консцентианетическим (от лат. concentia - сознание), или консцентианетикой. Ключевые слова: публичное управление, парадигма публичного управления, коммуникация, управленческое сознание, сознательное управление, консцентианетика

$\Pi$ оиск управленческой парадигмы, начавшийся как реакция на кризис публичного управления и хронологически совпавший с кризисом государства всеобщего благоденствия (80-е гг. прошлого столетия), породил целую череду концепций и подходов (от нового государственного менеджмента до менеджмента публичных ценностей), нашедших отражение как в научной литературе, так и в практике публичного управления целого ряда стран [Сморгунов 2011]. Являются ли они относительно автономными направлениями теоретической мысли, каждое из которых по-своему стремится решить проблему управляемости, или органически вытекают из некоего общего основания как единого корня, не сводящегося ни к одному отдельно взятому направлению? В последнем случае такое основание и могло бы претендовать на статус парадигмы современного публичного управления. В поисках ответа на поставленный вопрос мы отвергаем путь отвлечения общих признаков, присущих упомянутым концепциям и подходам, ибо это означало бы встать на позиции формальной логики. Подойдем к вопросу с другого конца - начнем с установления причин, породивших кризис публичного управления. Можно считать установившимся в научном сообществе консенсус относительно того, что причиной кризиса публичного управления является резко возросшая сложность социальной жизни современных обществ, сложность самих этих обществ как социальных систем.

Часто в качестве эквивалента этой сложности используется термин «человекоразмерность». Вместе с тем попытки объяснить существо этих характеристик традиционными средствами сопряжены с существенными трудностями. Так, с системологических позиций сложность системы определяется числом элементов системы, числом образованных ими связей, а также свойствами самих элементов (подсистем). Однако ясно, что пространственно-количественные характеристики не являются исчерпывающими для схватывания сущности такого понятия, как человекоразмерность. Не меняет положения вещей и наделение элементов системы особыми свойствами, обусловливающими ее челове- 
коразмерность, - в этом случае встает другой, не менее сложный вопрос: в чем же состоит упомянутая «особость».

Забегая вперед, можно сказать, что она (эта особость) обусловлена, по-видимому, неисчерпаемостью исторически развивающейся личности индивида.

Таким образом, в отношении общества как объекта управления можно констатировать пока лишь то, что его человекоразмерные свойства, все в большей степени проявляющиеся в условиях современной действительности, являются фактором (и притом объективным), снижающим управляемость (что осознается интуитивно и наблюдается в реальной действительности). Также можно констатировать и несостоятельность применительно к человекоразмерным объектам тех методологических подходов, в которых доминирует формальная логика (системный анализ, кибернетика, общая теория управления), транслируемых затем непосредственно в управленческие концепции и подходы.

В этой связи А.Г. Барабашев указывает, что «административные механизмы управления, под которыми понимаются принципы и технологии разработки и принятия управленческих решений, не адекватны масштабу и глубине проблем: управленческие решения слишком часто выглядят бесчеловечными, не учитывающими сложность и новизну социальной жизни» [Барабашев 2016: 166].

Последнее обстоятельство порождает трудноразрешимые управленческие проблемы и на стороне субъекта управления. Покажем это на примере функционирования произвольного формального института, могущего представлять любую социальную организацию. Типичная структура такого института с необходимостью включает в себя институциональных агентов (атрибут), институциональные правила (фактор долженствования), искусственно создаваемый механизм принуждения к исполнению правил, цель и санкции. Применительно к рассматриваемой проблеме атрибут и механизм принуждения к исполнению правил могут интерпретироваться как, соответственно, объект и субъект управления. Можно указать следующие возникающие неопределенности, снижающие качество управления.

Во-первых, речь идет о неопределенности цели управления таким человекоразмерным объектом. Здесь может наблюдаться дивергенция интересов (целей) институциональных агентов и субъекта управления: если целью управления с точки зрения субъекта является выполнение правил, то целью институциональных агентов является та, которая была декларирована образованием самого института. Только при условии, что выполнение правил ведет к достижению манифестированной институциональной цели, указанные цели совпадают. Такое совпадение достигается лишь при условии возможности формализации соответствующего фрагмента реальной действительности, что исключено для человекоразмерных объектов. Кроме того, в условиях формального института трудно говорить о наличии консенсуса как относительно институциональной цели, так и относительно институциональных правил: нужно учесть то обстоятельство, что и те и другие могут изменяться во времени. С точки зрения субъекта управления, это означает необходимость творческого отношения к принятию управленческих решений как в отношении установления правил, так и в отношении их выполнения. Вторая неопределенность, связанная с оценкой качества управления, является прямым следствием неопределенности цели, в условиях которой однозначный выбор критериев такой оценки становится крайне затруднительным, если не сказать невозможным. Наконец, не менее важной проблемой для субъекта управления становится распознавание и адекватное восприятие проблемной ситуации. Уже из повседневного опыта нам известно, что если мы впервые сталкиваемся с тем или иным предметом или явлением, то, несмо- 
тря на то что чувственно воспринимаем его (т.е. видим, слышим, осязаем), никакого следа в нашем сознании он не оставит, как если его бы не существовало в реальности. Естественно, что такое созерцательное восприятие никак не может служить основанием для распознавания, а тем более для решения проблемной ситуации. Получается, что для того, чтобы распознать и познать ее, нужно уже что-то о ней знать, т.е. подойти к ней со знанием. Здесь мы впервые приходим к идее управленческого сознания и, соответственно, сознательного управления. К этому же нас подводит и приведенный выше анализ неопределенности цели управления. Между тем в сложившейся практике управления доминируют механистические, формальные подходы, сложившиеся в недрах административнобюрократических и менеджериальных моделей управления и получивших в них теоретическое обоснование. В результате субъект управления в значительной степени действует как робот или бессознательный автомат, использующий предписанные ему инструкции и программы, составленные для типовых проблемных ситуаций, а его творческий потенциал и управленческое сознание, по существу, искусственно блокируются. В этом заключается, на наш взгляд, вторая (субъективная) причина наступившего кризиса публичного управления. Кумулятивное действие выявленных причин имеет своим результатом все возрастающую степень несоответствия требованиям закона необходимого разнообразия Эшби. Человекоразмерность объекта управления настоятельно потребовала человекоразмерности и субъекта управления.

Поиск причин кризиса публичного управления (как и управления в целом) не только приводит нас к установлению таковых, но и выявляет очертания нового научно-методологического подхода, рассматривающего проблему управляемости через призму деятельностно ориентированого (в данном случае - управленческого) сознания. Такого рода сознаниецентризм дает нам основание назвать этот подход консцентианетическим (от лат. concentia- сознание), или консцентианетикой.

В основе предлагаемого методологического подхода лежит гипотеза о существовании единых механизма, закономерностей и условий формирования обыденного и любого деятельностно ориентированного (в частности, управленческого) сознания, оказывающихся в этом случае подобными в том смысле, что обладают одинаковым существенным свойством - способностью адекватно отражать соответствующие фрагменты реальной действительности. При этом специфика возникающего сознания определяется преимущественно спецификой самой предметной деятельности.

В процессе проецирования закономерностей и условий формирования обыденного сознания на управленческое важным представляется эксплицирование применительно к последнему тех из этих условий, которые являются естественными для обыденного сознания и поэтому в традиционной литературе специально не артикулируются. Кроме того, внимание должно быть уделено не только формированию управленческого сознания, но и вопросу его удержания, утраты и восстановления.

Решение перечисленных задач по формированию, удержанию и восстановлению управленческого сознания направлено, в конечном счете, на высвобождение творческого потенциала субъекта управления и на этой основе - на способствование решению проблемы управляемости человекоразмерными объектами.

Консцентианетика исследует феномен сознательности управления, поэтому следует уточнить, в каком смысловом значении здесь употребляется слово «сознательность». Таких значений, как известно, три:

1) основанность на сознании, способность адекватно отражать реальную действительность; 
2) ответственность, чувство долга;

3) намеренность, обдуманность.

По отношению к управлению второе и третье значения представляются атрибутивными, а употребление конструкции «сознательное управление» - тривиальным. Не так обстоит дело с первым смысловым значением сознательности, а именно на нем делается акцент в консцентианетике с присоединением при этом двух других значений как само собой разумеющихся. Уже опыт обыденного сознания указывает нам на существование целого спектра его состояний, отнюдь не все из которых являются состояниями «в норме» (эти отклоняющиеся от нормы состояния мы будем называть квазисознанием). Факторы, провоцирующие наступление квазисознательных состояний, многочисленны и разнообразны - шоки, необычные ситуации, внушения, не говоря уже о патологиях. Даже временные, преходящие состояния квазисознательности могут иметь нежелательные последствия в плане осуществления какой-либо деятельности (в случае управления - его провал).

Рассмотрение вопроса о том, как формируется обыденное сознание (аналогом которого, как предполагается, является интересующее нас управленческое сознание), мы начнем с того исходного положения, которое и подвело нас к идее сознательного управления: для того чтобы предмет, явление внешнего мира были индивидом осознаны и адекватно восприняты, нужно некое предварительное знание о них, или короче - для формирования сознания требуется предзнание. Обращение к этому исходному положению позволяет сформулировать три ключевых вопроса, ответы на которые, во-первых, ведут нас к пониманию основных моментов в механизме формирования человеческого сознания, а во-вторых, обозначают главные этапы и направления теоретической мысли (в первую очередь философской), имеющей своей целью постижение этого механизма. Упомянутые вопросы могут быть сформулированы следующим образом.

1. Почему сознание не может быть сформировано на основе одного только чувственного, созерцательного восприятия объекта внешнего мира без привлечения предзнания?

2. Что представляет собой и как образуется это предзнание?

3. Как соотносятся индивидуальные чувственные знания и предзнание в процессе формирования сознания?

Попытки дать положительный ответ на первый вопрос адептами субъективного идеализма, исходившими из того, что сознание возникает в веществе мозга человека под чувственным воздействием предметов внешнего мира, окончились неудачей. Оказалось, что, во-первых, образ восприятия формируется не по схеме «сургуч - печать», а гораздо более сложным и опосредованным путем. А во-вторых, сознание и мышление оперируют именами и понятиями, в которых всегда есть знание основного, необходимого и не имеющего конкретного материального прототипа, тогда как любое чувственное впечатление фиксирует лишь внешнюю форму единичных предметов.

Что касается природы и сущности предзнания (общественное знание), то, согласно впервые объяснившему его Гегелю, оно представляет собой всю «совокупность вещей, окружающих человека - тело человеческой цивилизации, созданное в результате деятельности многих поколений людей, их опредмеченная история, застывший и успокоившийся в своем естественном воплощении мир духа, сознания» [Михайлов 1976: 111]. При этом индивидуальное сознание человека формируется в его индивидуальной истории, повторяющей все основные этапы развития общественной культуры, за счет постепенного приобщения индивида к духовной сокровищнице человечества в целом.

Диалектическое разрешение обнаруживаемого здесь противоречия между 
всеобщим (общественным) и индивидуальным (особенным) по вопросу первичности Маркс увидел в исторически развивающейся совместной предметной деятельности и общении людей. В акте предметного действия как раз и обнаруживается внутренняя раздвоенность, диалогичность и даже расстроенность его структуры: «предмет действия, тот, с кем индивид действует совместно, предметно представший перед ним помощник и критик, который оценивает действия индивида, сравнивая их со своим (как с общественно значимым эталоном)» [Михайлов 1976: 282], и, наконец, сам индивид, выступающий для него в той же роли. Этот эффект расслоения и переживается индивидом как сознание.

Точно так же и субъект публичного управления, вовлеченный в процесс деятельностной коммуникации с обществом (прежде всего, с гражданским) как с объектом управления, обретает управленческое сознание - способность адекватно воспринимать и разрешать управленческие проблемы (что и составляет предмет управленческой деятельности). Эта адекватность достигается тем, что субъект сознательного управления воспринимает и разрешает проблемы не на основе формальных абстрактно-созерцательных алгоритмов, а как человекоразмерные, т.е. выраженные (измеренные) в контексте понятий, категорий и ценностей, а значит и в контексте логики исторического развития данного общества, в ходе которого они сформировались. Эксплицирование деятельностной коммуникации как основы формирования управленческого сознания делает не менее важной и артикуляцию тех ее важнейших характеристик, которые и обусловливают эту ее (коммуникации) роль. К таким характеристикам следует отнести:

- непрерывный характер: прекращение ее или длительный перерыв неизбежно приводит к деградации управленческого сознания (наподобие эффекта Маугли в случае сознания обыденного);

- мотивированный самой жизненной необходимостью характер: в противном случае коммуникация была бы формальной, в процессе интериоризации управленческой проблемы отсутствовал бы момент сопереживания, отождествления субъектом управления этой проблемы с моментом его личной биографии.

Придание таких свойств деятельностной коммуникации, приводящее к формированию управленческого сознания, означает перестройку всей управленческой культуры и не может быть осуществлено одномоментно. Упомянутая мотивация, например, немыслима без развитой демократии, которая сама есть результат деятельности многих цивилизационных факторов. Более того, вытекающие из теории общественного выбора изъяны как прямой, так и представительной демократии не позволяют сделать вывод о гарантированном формировании развитого публичного управленческого сознания. Вместе с тем в реальности существует весьма действенный, хотя и жесткий инструмент преодоления теоретических затруднений - естественный эволюционный отбор. Можно утверждать, что тенденция к одухотворению (консценциализации) социальных систем (формированию управленческого сознания) является мейнстримом современного этапа эволюции социальной материи подобно тому, как эволюция живой природы на определенном этапе исторического развития завершилась появлением homo sapiens. Те сообщества, которые в наибольшей степени преуспеют в формировании сознательного управления, и окажутся лидерами современного общественного развития.

Если обратиться теперь к сформулированному в начале статьи вопросу, то в свете изложенного нетрудно заметить, что упоминавшиеся концепции публичного управления отражают либо те или иные грани управленческого сознания (когнитивный, аксиологический подходы), либо различные способы организации деятельностной коммуникации (политические сети, координацион- 
ное государство, концепция Smart City и т.п.), т.е. органично произрастают из концепции сознательного управления как единого основания, что и делает, на наш взгляд, обоснованными и ее претензии на статус современной парадигмы публичного управления.

Концептуализация сознательного управления, встроенность ее как в мейнстрим эволюции социальной материи, так и в парадигму постнеклассической науки способна придать необходимый импульс и вектор развитию и теории, и практики публичного управления.

\title{
Список литературы
}

Барабашев А.Г. 2016. Кризис государственного управления и его влияние на основные административные парадигмы государства и бюрократии. - Bопросы государственного и муниципального управления. № 3. С. 163-194.

Михайлов Ф.Т. 1976. Загадка человеческого Я. М.: Издательство политической литературы. 287 с.

Сморгунов Л.В. 2011. В поисках управляемости: трансформация теории публичного управления в XXI веке. - Вестник Санкт-Петербургского универсиmeта. Сер. 6. Вып. 4. С. 85-95.

BOLSHAKOVA Yulia Mikhailovna, Cand.Sci. (Pol.Sci.), Senior Researcher at the Institute of Political Psychology and Applied Political Studies, Pushkin Leningrad State University (10 Peterburgskoye Highway, Pushkin, St. Petersburg, Russia, 196605; academy.prof.com@gmail.com)

\section{IN SEARCH OF A PARADIGM OF PUBLIC MANAGEMENT: CONSCENTIANETICS - CONSCIOUS MANAGEMENT}

\begin{abstract}
The aim of the work is the conceptualization of conscious management as a paradigm of modern public administration. The methodology is based on the institutional, consciousness-centered approach, the dialectical, historical approaches, and the use of the analogy method.

The paper proposes a concept of conscious management, claiming to be the paradigm of modern public administration. The author shows that the objective cause of the crisis of modern public administration is the increased dynamics of changes in the socio-political life of modern societies. The use of theories emanating from formal logic and blocking the creative potential of the subject of management has been established as subjective reasons. The author concludes about the validity of the claims of the concept of conscious management on the role of the paradigm of modern public administration and proposes new methodological approach, which is based on the hypothesis of the existence of a single mechanism, laws and conditions for the formation of everyday and any activity-oriented (in particular, managerial) consciousness.

Keywords: public administration, paradigm of public administration, communication, managerial consciousness, conscious management, conscentianetics
\end{abstract}

